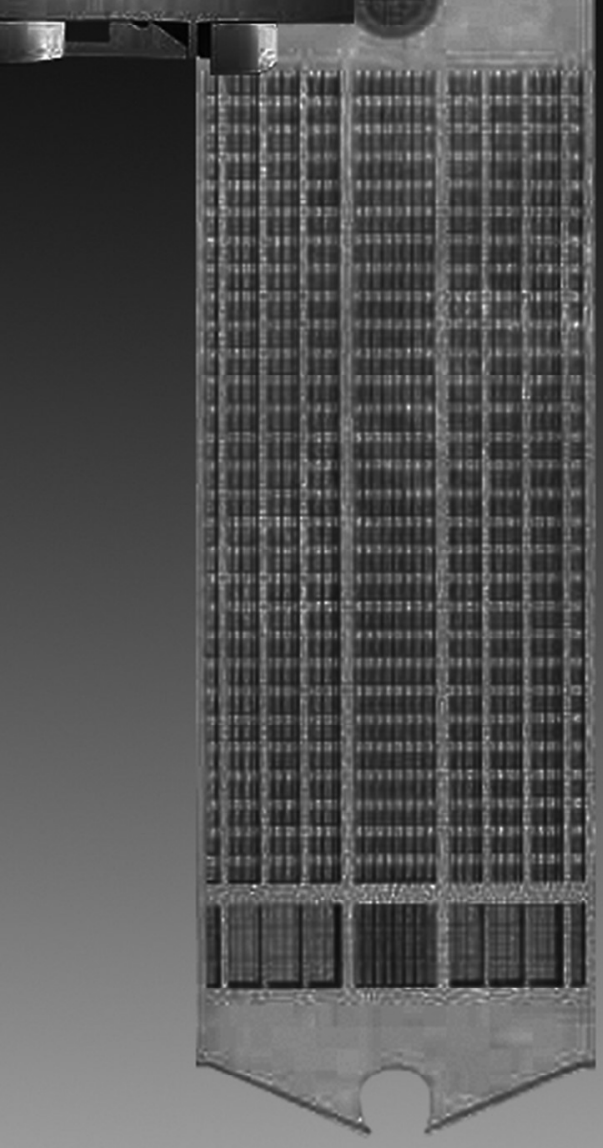




\section{Arquitectura y turismo}

La arquitectura y el turismo son entes inseparables y por lo tanto logran complementarse directamente. Desde la creación de espacios destinados para el transporte -aeropuertos, estaciones de tren o terminales de buseshasta espacios para la visita específica de turistas -museos, bibliotecas o alojamientos- podemos ver cómo la arquitectura y el turismo comparten el mismo espacio.

Si bien el turismo cultural busca tener una mirada en retrospectiva respecto a los espacios que se visitan, teniendo la posibilidad de relacionarse con la historia y la cultura de un lugar y tiempo determinados, la arquitectura como objeto del turismo logra hacer que el individuo no sólo mire, sino que también habite la historia de diferentes maneras. En este sentido, podemos mencionar dos continentes que guardan una fuerte relación entre su arquitectura y el turismo, contando con ciudades destinadas específicamente a los visitantes: Europa y América. En el primer caso, podemos ver ciudades como Roma o Atenas en donde la convivencia cotidiana con los edificios históricos logra establecer una continuidad entre el habitante de la ciudad y el turista y hacen que el turismo se convierta no sólo en algo visual sino también en algo experimental.

Desde el lado americano, tenemos ejemplos de ciudades como Cusco o Teotihuacán, en donde la experiencia turística se enfoca sobre todo en la visita a edificaciones históricas que representan hitos importantes en el territorio y que buscan atraer a los visitantes foráneos para mostrarles la grandeza de las civilizaciones antiguas.

A pesar que desde la edad antigua se puede registrar el desplazamiento de personas con motivos de ocio -los Juegos Olímpicos en Grecia por ejemplo-, el turismo nace como tal en el siglo XIX a partir de la revolución industrial y, con ella, la posibilidad de visitar lugares lejanos con relativamente poco tiempo de viaje.

Durante el siglo XX los viajes de turismo empiezan a hacerse cada vez más frecuentes y se organizan a partir de grupos de personas con gustos e intereses en común. Dentro de estos viajes, los relacionados con el arte y la cultura, la religión, la naturaleza o la gastronomía son los más frecuentes. En este sentido, la visita a museos se convierte en parte obligada de un itinerario de viaje y no es extraño pensar que este tipo de edificaciones nacen a partir de la modernidad.

Es en este momento, donde se toma valor de la historia como cuerpo compuesto del pensamiento y creación del ser humano a lo largo del tiempo, que se mira en retrospectiva tomando distancia entre la edad antigua y la edad moderna. Es así como a partir del siglo XX las ciudades y edificaciones del pasado son vistas como piezas de museo, históricas, a partir de las posibilidades retrospectivas que plantea el pensamiento del ser humano del siglo XX.

Es importante determinar el papel fundamental del movimiento moderno en la concepción de la historia de la arquitectura, ya que las migraciones profesionales y los viajes de estudio se acentúan en este momento y, además, la figura del arquitecto como autodenominado creador de cultura se levanta por encima de las necesidades mismas de la sociedad. En este momento de cambios radicales en el plano social, económico y cultural, la arquitectura toma un giro importante hacia la presencia del arquitecto como personaje intelectual, por tanto persona que debe ser escuchada, y al objeto arquitectónico como obra de arte, que debe ser admirada.

Durante el siglo XX, con la revolución industrial y las mayores posibilidades de viaje, se desarrolla un fuerte intercambio entre arquitectos de diferentes partes del mundo, en algunos casos como viajes de estudio, otros como giras de divulgación arquitectónica y otros escapando de realidades hostiles en busca de un nuevo horizonte. Los grandes maestros del siglo XX comien- 


\section{ARQUITEXTOS 29}

zan a desplazarse fuera de sus ciudades o países para aprender e internacionalizar un nuevo pensamiento arquitectónico.

Se pueden revisar los casos de Walter Gropius, Mies van der Rohe o Josep Lluís Sert cuando salen de Europa escapando de los conflictos políticos de sus países de origen y llegan a Estados Unidos para continuar una labor proyectual y académica de gran intensidad, dividiendo así su obra en etapas europeas y americanas. El maestro de la arquitectura norteamericana, Frank Lloyd Wright también realiza viajes de turismo arquitectónico importantes para luego incorporar esas experiencias a sus obras. En el caso de Wright, un viaje a Japón en el que tiene contacto con la arquitectura tradicional, logra conmoverlo e inspirar varias de sus casas en su etapa de La Pradera, reinterpretando los techos en voladizo y la utilización del fuego como elemento central en las áreas más familiares de la vivienda.

Posiblemente sea Le Corbusier uno de los personajes claves para entender el viaje arquitectónico como algo específico y particular que nace en el siglo XX. Revisando rápidamente su vida vemos dos viajes iniciales que marcan su actividad proyectual: el viaje de un mes por la Toscana a los 20 años y el viaje a Europa del este y Oriente Medio a los 23. En ambos viajes Le Corbusier completa una serie de dibujos de la arquitectura que visita, estudiando los ritmos y las formas clásicas así como la composición arquitectónica fuera de Europa. Estos viajes se verán marcados en sus primeras villas puristas, como por ejemplo en la villa Stein de Garches, donde se hace una clara referencia a la villa Malcontenta de Palladio en Venecia.

La segunda relación entre la arquitectura de Le Corbusier y el viaje se puede ver en la gran cantidad de proyectos fuera de Europa en donde resaltan el Museo de Arte Occidental de Tokio, así como la planificación urbana y edificios singulares para la ciudad de Chandigarh en India. En estos casos se ve la condición universal tanto del personaje como de la arquitectura moderna, convirtiéndose ya en destinos de viaje para arquitectos.

Finalmente el arquitecto suizo desarrolla un papel fundamental en la internacionalización y difusión de la arquitectura moderna, con lo que podemos señalar una tercera influencia en la relación entre arquitectura y turismo: es con sus viajes a América del Sur.

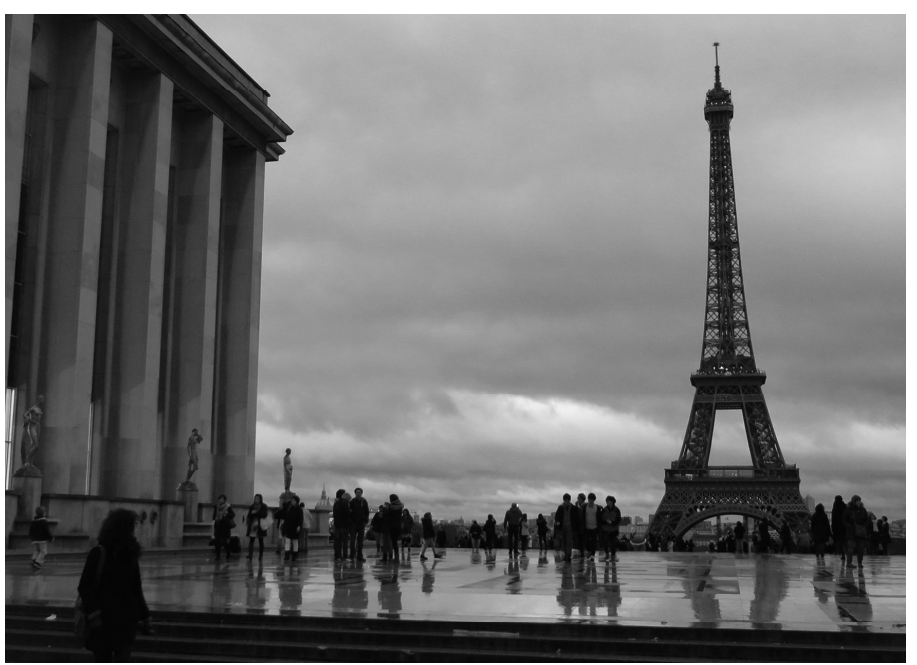

En su primera gira sudamericana visita las ciudades de Rio de Janeiro, Sao Paulo, Buenos Aires, Montevideo y Asunción, haciendo recorridos por diferentes escuelas de arquitectura, pero sobre todo, tratando de convencer a políticos y autoridades de realizar proyectos arquitectónicos de escala urbana que logren generar una visión moderna de la ciudad. En estas ciudades, podemos mencionar que los proyectos más importantes son los de Rio de Janeiro, con edificios - autopistas que buscan enmarcar el paisaje para beneficiar el ocio de la vida moderna, así como la intervención en Buenos Aires con un centro financiero que aspiraba a convertirse en el Nueva York del hemisferio sur.

En todos sus viajes, Le Corbusier fue recibido como una celebridad y logra consolidar una de las características más importantes de la arquitectura moderna: la internacionalización de un estilo y la rápida consagración de obras y personajes gracias a los medios de difusión arquitectónica. Será entonces a partir de estas dos variables, que los viajes arquitectónicos, esos realizados sólo por arquitectos, tomarán cada vez más fuerza e importancia como parte de la formación profesional.

\section{El arquitecto y el espejo}

En las últimas décadas, la arquitectura se ha dedicado cada vez más a mirarse a sí misma. Prueba de ello son los innumerables premios que se crean en diferentes partes del mundo, desde los reconocidos como bienales o premios por trayectoria, hasta los impulsados por el marketing o inventados por empresas privadas como medio de posicionamiento de su marca dentro del mercado de la arquitectura, el diseño y la construcción.
Vista de la torre Eiffel, París 
En nuestro medio, podemos ver que el desarrollo económico ha traído consigo un incremento en la producción arquitectónica que puede relacionarse con la aparición de revistas especializadas, nuevos premios para los arquitectos jóvenes, la creación de nuevas escuelas de arquitectura y una gran difusión de fotografías y proyectos que buscan "viralizarse", poniendo sobre el mapa a una ciudad, una obra y un arquitecto dentro del mundo del diseño. Este afán de protagonismo por parte del arquitecto, que ya viene sucediendo desde hace varias décadas, convierte muchas veces a la arquitectura en una imagen inmediata que busca un impacto directo y rápido en los observadores.

Sin embargo, esta exposición se da en el ámbito privado de la especialidad y son únicamente los arquitectos o estudiantes de arquitectura los que prestan atención a este tipo de imágenes, teniendo la arquitectura un nuevo valor: el de la inmediatez visual, que logra hacer que los arquitectos sean productores de fotografías estéticamente agradables dejando de lado su responsabilidad de fondo como creadores de la cultura edificada de una sociedad.

Podemos relacionar el inicio de este tipo de actitud frente al objeto arquitectónico $y$ al personaje del arquitecto con la modernidad y la vocación individualista que lleva al proyectista a nivel de artista, dejando muchas veces de lado a las personas que interactuarán o utilizarán sus obras. En la manera de representar y presentar la arquitectura moderna vemos que la abstracción de la imagen hace referencia al objeto arquitectónico aislado, por lo que no es extraño entender que a partir del siglo XX las isometrías y axonometrías sean el medio gráfico mediante el cual la arquitectura es representada, permitiendo ver de forma simultánea las plantas, cortes y elevaciones, así como las relaciones espaciales e incluso el diseño de mobiliario, pero obviando el contexto y la escala humana.

En este momento, la arquitectura empieza a tomar valor por sí misma, es decir, como objeto edificado. Sin embargo, los inicios de la modernidad plantean otros ideales entre los cuales se busca el desarroIlo social -sobre todo en la Europa de post guerra- o la creación de una nueva identidad nacional -como en la arquitectura usoniana de Wright y la Escuela de Chicago-. Se ve entonces que la modernidad tiene estos dos objetivos específicos relacionados, por un lado, a las posibilidades de industrialización como medio para el desarrollo social en contextos con crisis económicas, y por otro, a la posibilidad de construir una identidad y cultura propia en los contextos de bonanza económica. ¿Pero qué es lo que sucede con esta arquitectura una vez que se supera la crisis?

Comparando las situaciones planteadas anteriormente, vemos que la arquitectura en Estados Unidos construida por la Escuela de Chicago aún tiene un valor importante en la ciudad y las grandes metrópolis americanas son destinos obligados para el turismo arquitectónico y cultural. Ciudades como Nueva York o Chicago son visitadas constantemente por arquitectos y estudiantes de arquitectura que se pasean por las calles fotografiando los grandes rascacielos construidos durante el siglo XX. Reconocemos aquí a los grandes personajes como Sullivan, Burnham, Johnson e inclusive Mies van der Rohe, que logran atraer mediante su obra a los especialistas y profesionales que viajan a Estados Unidos en busca de inspiración.

Por otro lado, vemos la arquitectura moderna europea con una preocupación más relacionada a lo social, debido a los conflictos generados por la primera y segunda Guerra Mundial. En esta parte del mundo, las Exposiciones Universales que sirven para mostrar las capacidades constructivas de cada país no buscan la idea de monumentalidad arquitectónica, sino más bien solucionar a partir de la repetición los problemas de vivienda para ciudades que están en pleno crecimiento. Posiblemente sean Walter Gropius y Hannes Meyer los principales representantes del diseño modular en vivienda social europea, el primero con sus prototipos para Weissenhofsiedlung, y el segundo con la orientación que dio a la Bauhaus hacia temas sociales, cuando tomó la dirección de la escuela.

Debemos recordar, también, que el desarrollo de la arquitectura moderna en Europa y América fue muy diferente en términos ideológicos. Mientras en Europa los cambios se daban desde el arte y a partir de las revoluciones sociales que iban en contra de los gobiernos totalitarios, en Estados Unidos el desarrollo surge a partir de la ingeniería y se da como consecuencia del crecimiento económico e industrial de las 



1 Maxxi (Museo de Arte, siglo XXI) Roma.

2 Biblioteca España. Medellín.

3 Ciudad de la Cultura.

Santiago de Compostela.

4 Casa Milá. Barcelona.

5 Torres del Parque. Bogotá.

6 Villa La Roche - Jeanneret

Fundación Le Corbusier. París. 

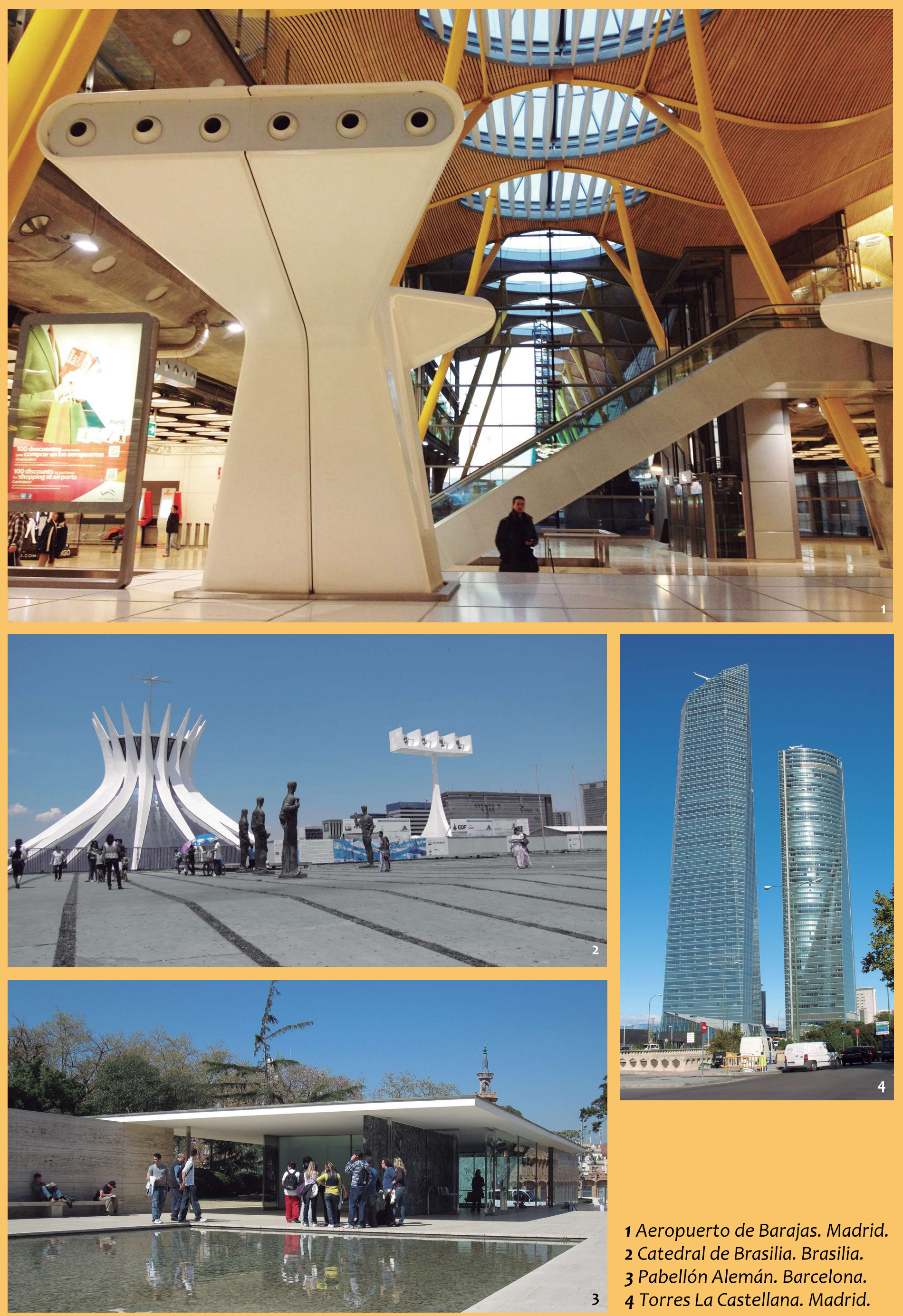

1 Aeropuerto de Barajas. Madrid. 2 Catedral de Brasilia. Brasilia. 3 Pabellón Alemán. Barcelona. 34 Torres La Castellana. Madrid. 
políticas liberales. Posiblemente por esto, es que la arquitectura moderna europea busca de manera más cercana la pureza de la forma y la creación de la obra de arte total al combinar el arte con la artesanía.

La primera etapa de Le Corbusier, la del purismo, es la que empieza a convertir todas estas nociones artísticas en la creación de objetos bellos que tengan una traducción directa en términos estéticos y geométricos. Los cinco puntos para una nueva arquitectura, que se ven establecidos claramente en la Villa Savoye, buscan liberar a la arquitectura del lenguaje del ingeniero para introducirla en la estética arquitectónica, creando así un objeto bello que guarda relaciones consigo mismo.

Lamentablemente, esta vocación de objetualizar la arquitectura y personificar al arquitecto tiene tal fuerza que en muchos casos vale más el objeto como obra de arte que como edificio funcional y utilitario. La pérdida de la escala humana y el poco entendimiento del ciudadano moderno lleva a la arquitectura a ser abandonada y dejada únicamente como una pieza de museo que será en el futuro visitada solamente por personas afines a la profesión. Podemos ver que en Europa este fenómeno se da con mucha intensidad, y gran parte de la arquitectura moderna que es entendida como "gran obra" queda abandonada para ser un destino turístico muy específico.

Como ejemplos, podemos ver las grandes infraestructuras desarrolladas por los arquitectos rusos, ahora abandonadas o transformadas totalmente para albergar nuevos usos. El proyecto EUR 42 a las afueras de Roma, encargado por Mussolini a Piacentini, en donde encontramos grandes edificios de Guerrini o Libera, están en la actualidad descuidados $u$ ocupados para otras funciones que no fueron previstas convirtiéndose en una especie de barrio fantasma. El propio edificio de la Bauhaus en Dessau y las casas de artistas, antes la escuela más importante de arquitectura del mundo y hogar de los mejores artistas modernos, transformados ahora en museo y tienda de souvenires. Las espectaculares casas de Antoní Gaudí y la Sagrada Familia se convierten en destinos específicos dentro de los recorridos turísticos de Barcelona -en este caso para arquitectos o no arquitectos- y la reconstrucción del Pabellón Alemán de Mies van der Rohe en la misma ciudad, que alberga ahora una tienda de recuerdos (para arquitectos) con la frase "less is more".

Como vemos, la arquitectura moderna europea pasó de ser movimiento revolucionario y autodenominado traductor del estilo de vida moderno a destino turístico abandonado que busca ser conservado y rescatado a partir de las iniciativas de los arquitectos.

Posiblemente las obras de Le Corbusier sean el destino más importante para el turismo arquitectónico y sean las que mejor están preparadas para recibir turistas. El arquitecto suizo, que para la década de 1920 crea el Plan Voisin para el centro de París -transformando totalmente su trama urbana y edificaciones tradicionales-, es ahora el arquitecto más afamado por los seguidores del siglo XX que buscan a toda costa conservar su obra. A pesar de su gran importancia e influencia dentro del pensamiento arquitectónico moderno -e inclusive con extensión hasta el día de hoyvemos que casi la totalidad de sus edificios se han transformado en espacios inhabitados y abierto a los turistas arquitectos que buscan reencontrarse con el maestro. La lista de edificaciones puede ser extensa: la mundialmente conocida Villa Savoye, que fue habitada durante poco tiempo por sus propietarios para pasar a ser una lección de arquitectura moderna construida, la ViIla Stein y la Villa La Roche, ambas acondicionadas como espacios de exposición de la casa misma, es decir, una caja vacía para ser recorrida y admirada. La casa Curutchet, que ha tenido que ser tomada por el Colegio de Arquitectos de La Plata para poder ser conservada una vez que dejó de utilizarse por sus propietarios. La capilla de Ronchamp, creada como llegada del camino de peregrinación de fieles religiosos, convertida ahora en llegada del camino de peregrinación de fieles arquitectónicos. La Unidad Habitacional en Marsella, que no llegó a tener el éxito esperado como prototipo de vivienda, es ahora punto de visita obligatorio si se está en Francia y se es arquitecto.

En Estados Unidos la situación cambia debido a la vocación de los edificios modernos. Al norte de América el desarrollo de la arquitectura moderna se vio encarnado en la capacidad constructiva de la ingeniería y en la potencia económica de las empresas, por lo que la construcción se orientó a los grandes rascacielos de oficinas que siguen 
vigentes hasta el día de hoy. Sin embargo vemos que sí existen edificios-museo en lo que respecta a la vivienda unifamiliar moderna, donde los más representativos, como la casa Kaufmann de Frank Lloyd Wright o la casa Farnsworth de Mies van der Rohe, son ahora museos y lugares de visita. La primera fue declarada monumento nacional de Estados Unidos y catalogada como la mejor obra de arquitectura norteamericana de la historia por el American Institute of Architects. En el caso de Mies van der Rohe, después de muchas discusiones entre el arquitecto y el cliente, la casa fue abandonada y nunca habitada para transformarse luego en un espacio de recorrido turístico especializado.

En Estados Unidos se da también otro fenómeno: la creación de residencias dentro de las universidades, que finalmente pasarán a ser parte del campus y por lo tanto espacios de estudio para los universitarios y de visita para los turistas. Los casos más importantes son las residencias de Josep Lluís Sert y Walter Gropius en Harvard y la casa Robbie diseñada por Frank Lloyd Wright para un profesor de la Universidad de Chicago.

Podemos ver que la arquitectura moderna ha pasado de ser traductora de las necesidades del ser humano del siglo XX a convertirse rápidamente en piezas de arte aislado para la visita de turistas especializados. ¿De qué manera entonces puede tener validez una arquitectura que se convierte en obsoleta para su función original? ¿Es que acaso la arquitectura moderna está condenada a ser simplemente una obra de arte deshabitada? ¿Estamos los arquitectos tan desconectados de la sociedad que debemos crear nuestras propias piezas de museo?

\section{La arquitectura como valor cultural}

Para empezar a responder las preguntas planteadas líneas arriba, es importante entender dos puntos fundamentales: el por qué la arquitectura moderna -y sobre todo la vivienda- no tiene una continuidad de uso hasta el día de hoy, y por qué se buscan preservar estas cajas vacías como lugares de estudio y turismo. Sobre estos puntos, trataré de esbozar algunas ideas sobre el segundo, dejando el primero abierto al diálogo y a otro número de ARQUITEXTOS.

Pareciera que la arquitectura y los arquitectos buscan generar sus propios mecanismos de supervivencia, instaurados desde las escuelas de arquitectura que por un lado idealizan a los maestros (sobre todo a los proyectistas, creadores de objetos artísticos) y que enseñan muchas veces las imágenes de los edificios importantes sin tener un claro entendimiento del trasfondo cultural en el que se generan ciertas obras arquitectónicas. Esto hace que la arquitectura sea leída como un simple fenómeno formal cometiendo el mismo error que la arquitectura moderna al borrar de sus imágenes y fotografías a las personas que habitarán los edificios -incluso en algunos casos, como Le Corbusier, introduciendo su automóvil como parte de la ambientación- para pasar a la admiración del objeto aislado, dejando de lado los principios culturales, climáticos o humanos que se puedan relacionar con la arquitectura.

Otro mecanismo de supervivencia es la valoración, o en muchos casos sobre valoración, del objeto arquitectónico, buscando el reconocimiento inmediato como obra trascendental sin dejar que se tome una distancia temporal con la obra y el proyectista; lo que podemos constatar con los innumerables premios y reconocimientos que se dan a los arquitectos por haber realizado tal o cual gestión u obra. En este punto se puede mencionar la idea del canon planteada por Peter Eisenman, donde se nos explica que el valor del edificio canónico frente a la gran obra es que la importancia del primero debe ser medida a partir de sus proyecciones a futuro -lo que constituye un corpus arquitectónico más amplio- y más bien la gran obra ofrece una lectura en sí misma, aislada de todo tiempo y espacio y por lo tanto irrepetible. Entender por ejemplo que el Altes Museum (1830) de Schinkel tiene valor no solo como obra en sí misma, sino porque inspira a edificios posteriores como el Crown Hall (1956) de Mies van der Rohe o el edificio Peter B. Lewis (2002) de Frank Gehry es lo que permite tener una lectura de la obra arquitectónica como un aporte a la cultura del momento y a la futura.

$Y$ finalmente, el tercer mecanismo de supervivencia que puede tener la arquitectura podría ser entendido como la consecuencia del primero y el segundo: la institucionalización del edificio para convertirse en pieza aislada y por lo tanto visitable por los especialistas de la materia. En este sentido, ya se ha generado un público expectante que está dispuesto a visitar las grandes obras de los grandes maestros, y por otro se ha logrado 
generar un sistema publicitario apoyado por las fotos, historias y chismes, redes sociales, tiendas de souvenires y tours a la medida de todos los bolsillos, para hacer que los arquitectos viajen a encontrarse con las imágenes que han visto en clases, libros y revistas.

Por otro lado es extraño ver que este fenómeno de la especialización del turismo arquitectónico se de sobre todo en la arquitectura moderna, en donde a pesar de algunas excepciones muy puntuales -como el caso de Gaudí y su extensión como estandarte turístico de la ciudad de Barcelona- los edificios habilitados como museos o galerías son visitados únicamente por arquitectos, mientras que la arquitectura precedente tiene un carácter turístico más universal. Ciudades como Roma, París, Cusco o Atenas son visitadas anualmente por miles de turistas que no tienen ninguna relación con la arquitectura y buscan más bien tener un contacto con la cultura que esta arquitectura logra albergar: nadie visita el Coliseo Romano para tratar de averiguar cómo se colocaban los ladrillos en la segunda y tercera arquería de la fachada. Sin embargo, Brasilia o incluso Medellín, son ciudades que se visitan casi de forma específica para ver sus edificios como piezas de museo o de ciudad-museo en este caso.

$\mathrm{Y}$ esto se da porque la arquitectura es, justamente, una proyección de la cultura de su época, una construcción que aporta valor cultural a los espacios en los que se desarrolla, porque habla de una voluntad del ser humano por tratar de innovar y avanzar hacia delante, como dirían los modernos, buscan ser enanos en hombros de gigantes.

Esta especialización que se ve claramente en la monumentalización de toda la arquitectura moderna europea y la desaparición de la latinoamericana, se da por un alejamiento del arquitecto de espacios sociales a los que antes pertenecía, para ensimismarse y cerrarse en un círculo seguro en donde todos hablen el mismo idioma y todos entiendan que lo más importante es en muchos casos la foto de la obra y la fama del personaje, antes que la real trascendencia de la obra y su proyección a la sociedad.

\section{Y finalmente...}

Si bien la idea de la arquitectura moderna como destino turístico nos ha ayudado a plantear algunas pautas sobre la situación actual del arquitecto y sus obras, es impor- tante entender que, aparentemente este síntoma de convertir al arquitecto en artista y a su arquitectura en obra de arte, por lo tanto pieza de museo o destino turístico, se da también en la arquitectura contemporánea. Eso, lo que hace, es aislarnos cada vez más de los círculos en donde se desarrolla la cultura y la sociedad, esa tremenda mayoría que cada día nos ve con justa razón como personajes accesorios.

Se debe entender que la importancia de la modernidad se debe a sus ideas e ideales y no a las formas puras, definidas e internacionales con las que se lee superficialmente. La modernidad es un fenómeno bastante más complejo e interesante que el conservar una obra deshabitada para abrirle las puertas al turismo especializado.

El arquitecto posiblemente debe dejar de lado las ansias protagónicas y escuchar y entender de manera más humilde la verdadera trascendencia de nuestra profesión, la verdadera necesidad de contar con la arquitectura en nuestras ciudades y ser piezas fundamentales de la construcción cultural del espacio en el que nos situamos.

$\mathrm{Y}$ mientras reflexiono en esto, pienso también en mi próximo viaje, que como arquitecto no será a una playa paradisiaca, sino seguramente a una ciudad densa e intensa para buscar alguna casa-museo de algún arquitecto-estrella que aún no he podido visitar.

Links y destinos turísticos sólo para arquitectos (a manera de bibliografía)

\section{Ciudades}

Barcelona: www.architectours.com Brasilia: www.quierobrasil.com Nueva York: www.newyorkarchitecture.info Medellín: www.guiaturisticademedellin.com Chicago: www.chicagoline.com

Museos

Museo Nacional de Arquitectura: www.museonacionaldearquitectura.bellasartes.gob.mx MARQ: www.socearq.org

Museo de Arquitectura Leopoldo Rother: www.facartes.unal.edu.co

Museum of Architecture: www.time-imabari.jp Edificios

Villa Savoye: www.villa-savoye.monuments-nationaux.fr Casa Kaufmann: www.fallingwater.org.

Edificio Seagram: www.375parkavenue.com Casa Farnsworth: www.farnsworthhouse.com Bauhaus en Dessau: www.bauhaus-dessau.de Casa Milá: www.lapedrera.com

Fundaciones

Fundación Le Corbusier: www.fondationlecorbusier.fr Fundación Mies van der Rohe: www.miesben.com Fundación Antoní Gaudí: www.casamuseugaudi.org Frank Lloyd Wright Foundation: www.franklloydwright.org Fundación Docomomo: www.docomomo.com 